\title{
The urosome of the Pan- and Peracarida
}

\author{
Franziska Knopf ${ }^{1}$, Stefan Koenemann², Frederick R. Schram³ ${ }^{3}$ Carsten Wolff ${ }^{1}$ \\ (authors in alphabetical order) \\ ${ }^{1}$ Institute of Biology, Section Comparative Zoology, Humboldt University, Philippstrasse 13, 10115 Berlin, \\ Germany, e-mail: knoepfchen1705@web.de; ${ }^{2}$ Institute for Animal Ecology and Cell Biology, University of \\ Veterinary Medicine Hannover, Buenteweg 17d, D-30559 Hannover, Germany; ${ }^{3}$ Dept. of Biology, University \\ of Washington, Seattle WA 98195, USA.
}

Key words: anus, Pancarida, Peracarida, pleomeres, proctodaeum, teloblasts, telson, urosome

\begin{abstract}
We have examined the caudal regions of diverse peracarid and pancarid malacostracans using light and scanning electronic microscopy. The traditional view of malacostracan posterior anatomy is not sustainable, viz., that the free telson, when present, bears the anus near the base. The anus either can occupy a terminal, sub-terminal, or mid-ventral position on the telson; or can be located on the sixth pleomere - even when a free telson is present. Furthermore, there is information that might be interpreted to suggest that in some cases a telson can be absent. Embryologic data indicates that the condition of the body terminus in amphipods cannot be easily characterized, though there does appear to be at least a transient seventh segment that seems to fuse with the sixth segment. Our understanding of the genesis of the so-called telson of amphipods could be subject to alternative interpretations than those traditionally put forth.
\end{abstract}

\section{Contents}

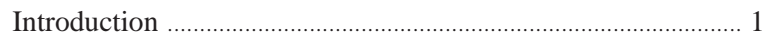

Material and Methods ................................................................... 2

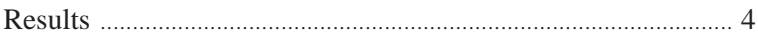

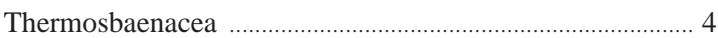

Mysida and Lophogastrida ............................................................ 4

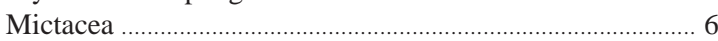

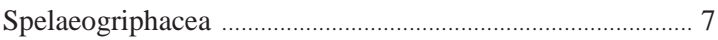

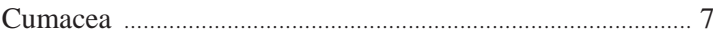

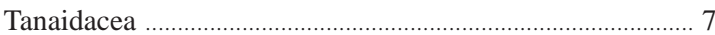

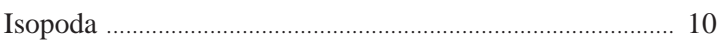

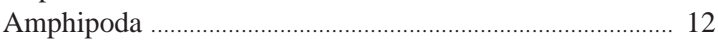

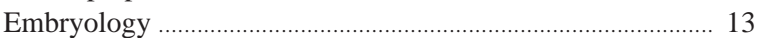

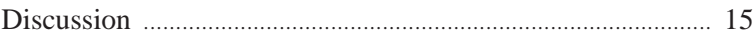

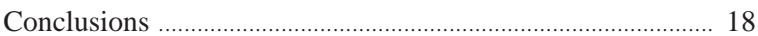

Acknowledgements ................................................................... 19

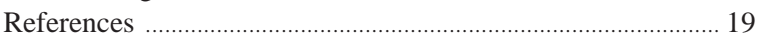

\section{Introduction}

The variation encountered in the caudal tagma, or posterior-most body region, within crustaceans is striking such that Makarov (1978), so taken by it, suggested that this region be given its own descriptor, the urosome. In the classic interpretation, the so-called telson of arthropods is homologized with the last body unit in Annelida, the pygidium (Westheide and Rieger, 1996; Grüner, 1993; Hennig, 1986). Within that view, the telson and pygidium are said to not be true segments because both structures supposedly lack coelomic sacs and ganglia. Likewise, the telson of adult arthropods has been defined as the structure, or region, arising from the posteriormost component of the germ band behind the segment segregating growth zone as demarcated by the teloblasts (Calman, 1909), and such a definition also applies to the pygidium of annelids (Anderson, 1973).

Debate about the nature of the caudal tagma has not been frequent, but when it has occurred it has been contentious. Sharov (1966) and Bowman (1971) argued from the viewpoint of gross anatomy that the definition of a telson in crustaceans depends on the presence and location of the anus. According to this line of reasoning two types of non-homologous urosomes can be distinguished: one type, possessing caudal rami and a terminal anus, is not a telson but rather a true body segment, or anal somite; the other type, exhibiting no caudal rami and with the anus opening on the antero-ventral surface, is a true telson. Schminke (1976) forcefully argued against this in- 
terpretation and made detailed reference to the complex caudal region of the bathynellacean syncarids, which exhibit both uropods and relatively elaborate caudal rami.

A parallel issue concerns the presence, location, and numbers of teloblasts vis-a-vis the urosome. True segments are said to occur anterior to this zone of active cell proliferation. However, Amphipoda lack ectoteloblasts entirely (Scholtz and Dohle, 1996), and the absence of these cells makes it difficult to evaluate what is or is not segmental ectoderm in the group, at least when applying the traditional definition. All the ectodermal cells in amphipods arise out of a process of cell segregation into bands on the germinal disc (Wolff and Scholtz, 2002). In Artemia, an active growth zone of cells rather than teloblasts generates a mass of tissue for subsequent differentiation without employing any regular cleavage or segregation pattern (Gilbert, 1997).

The advent of developmental genetics has provided other criteria to assess cell status. Segments can now be located based on expression patterns of segmentation genes such as engrailed (Patel, 1994; Scholtz, 1993, 1995), rather than relying on the location of teloblasts. However, this too must be used with caution. For example, Scholtz (1995) described the patterns of engrailed striping in the crayfish Cherax destructor. The pleon in this species develops anterior to the broad, long, bilobed mass of the presumptive telson. The formation of engrailed stripes appears in stages as the germ band grows posteriorly. At $60 \%$ of development, the first six pleomeres are delineated by stripes of engrailed across the entire width of the pleon. However, two additional stripes, a seventh and an eighth, also are present in the center part of the presumptive telson. At $65 \%$ development a further ninth stripe briefly appears. Pleomeres 1 through 7 also express engrailed in the Anlagen of their ganglia, while the eighth and ninth ectodermal engrailed stripes disappear by the time of $70-75 \%$ development. The first seven ganglia of the Cherax pleon display the characteristic CNS pattern of double commissures. An Anlage of the eighth ganglion forms but possesses only a single commissure. Nevertheless, out of this ganglion two nerves extend posteriorly into the presumptive telson. The ninth stripe completely disappears, while the Anlagen of ganglia 6 through 8 eventually fuse to form a single unit. One might ask whether the 'telson' of Cherax is segmental in nature, i.e., composed of fused segments along with the telsonic portion.

Thus the pattern of segmentation vis-a-vis the posterior pleon and the presumptive telson are not nearly as easy to characterize in fact as the classic anatomical definitions of the eumalacostracan caudal region would lead us to believe. We believe that the issues raised during the debates of the 1970s about the crustacean body terminus are not settled and are worthy of an across the board study of all crustacean urosomes.

\section{Material and methods}

We included a wide array of representative species from all pan- and peracarids in this study (Table 1). Specimens were chosen from the various orders for the diversity of form they display. All specimens came from the crustacean collection of the Zoological Museum, University of Amsterdam.

Initially, camera lucida drawings of the posterior body regions of specimens were made, though only a few are included herein. Subsequently, appropriate specimens were chosen for examination with electron microscopy (species with an asterisk in the appendix) with a JEOL JSM-35C scanning electron microscope.

In addition, we studied 4-d multi-layered photographic sequences of early development in the amphipod Orchestia cavimana showing the process of anus formation.

Fig. 1. Thermosbaenacea. (1) Thermosbaena mirabilis, pleon (ventral view), with anus opening terminally on the pleotelson. (2) T. mirabilis, habitus (lateral view), with uropods inserting at a medium level on the pleotelson (from Wagner, 1994). (3) Tethysbaena texana, pleomere six and telson, dorsal view. (4) T. texana, pleomere six, telson and left uropod, ventral view, with anus situated subterminally on the free telson. (5) Tethysbaena calsi, pleomere six, telson and uropods, ventral view, with anus almost terminal on telson. (6) T. calsi, telson, dorsal view (from Wagner, 1994). (7) Halosbaena acanthura, posterior part of pleon, ventral view, with anus situated mid-ventrally on telson. (8) H. acanthura, telson dorsal view (from Wagner, 1994). a = anus, pl 6 = pleomere 6, pt = pleotelson, $\mathrm{t}=$ telson (free), $\mathrm{u}=$ uropod. 

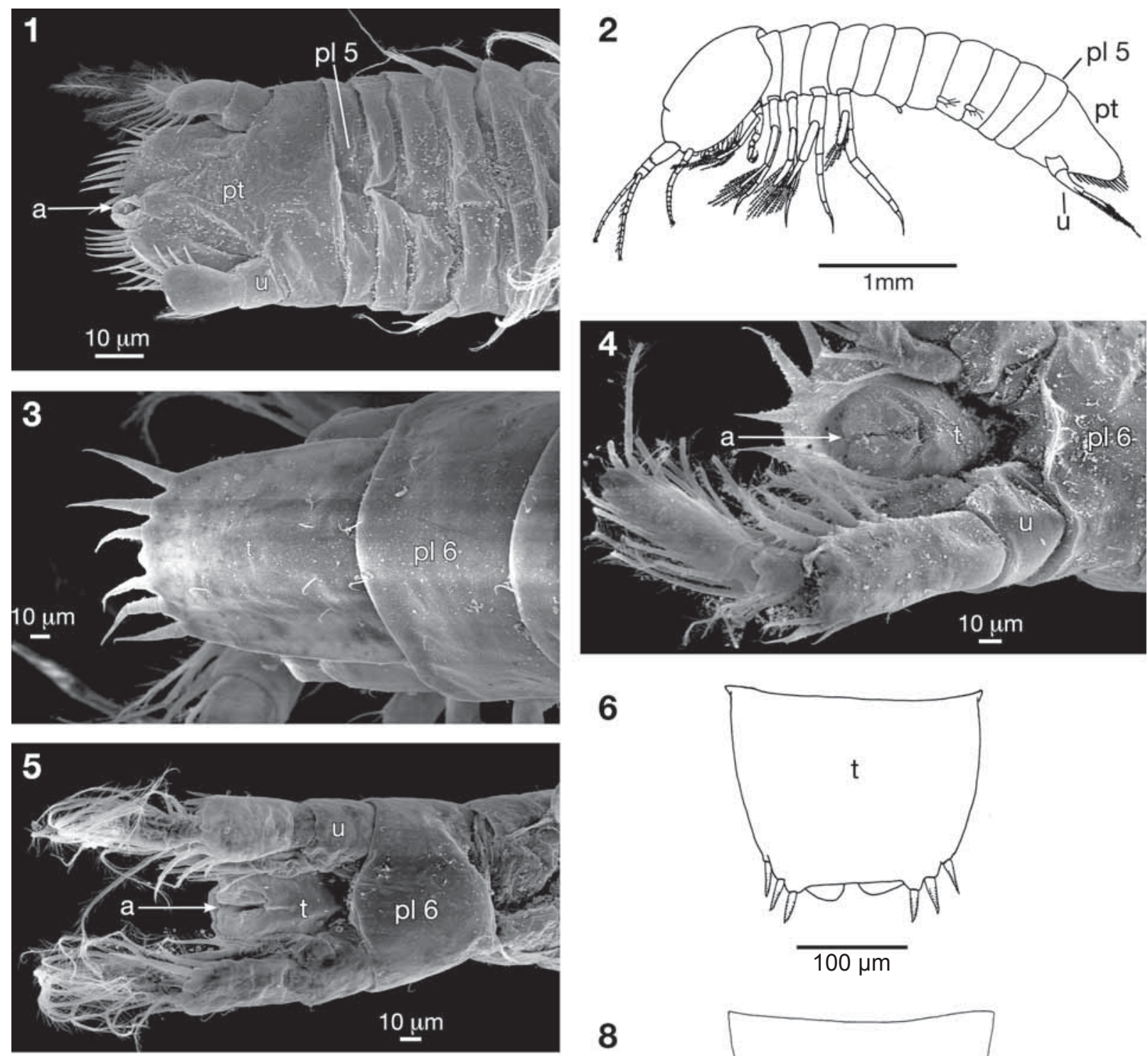

6
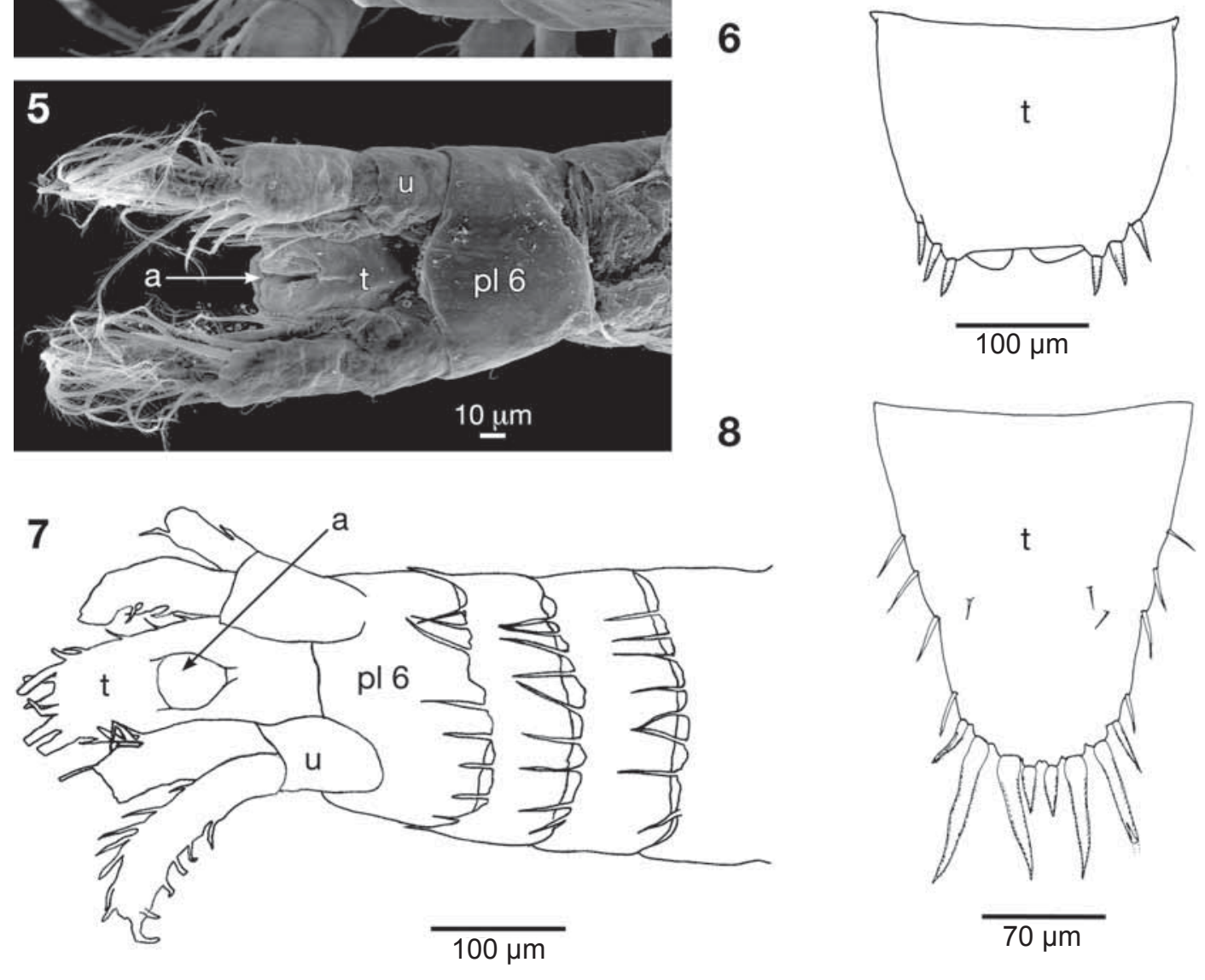
Table 1. Extant species examined for this study. * Designates taxa studied with SEM.

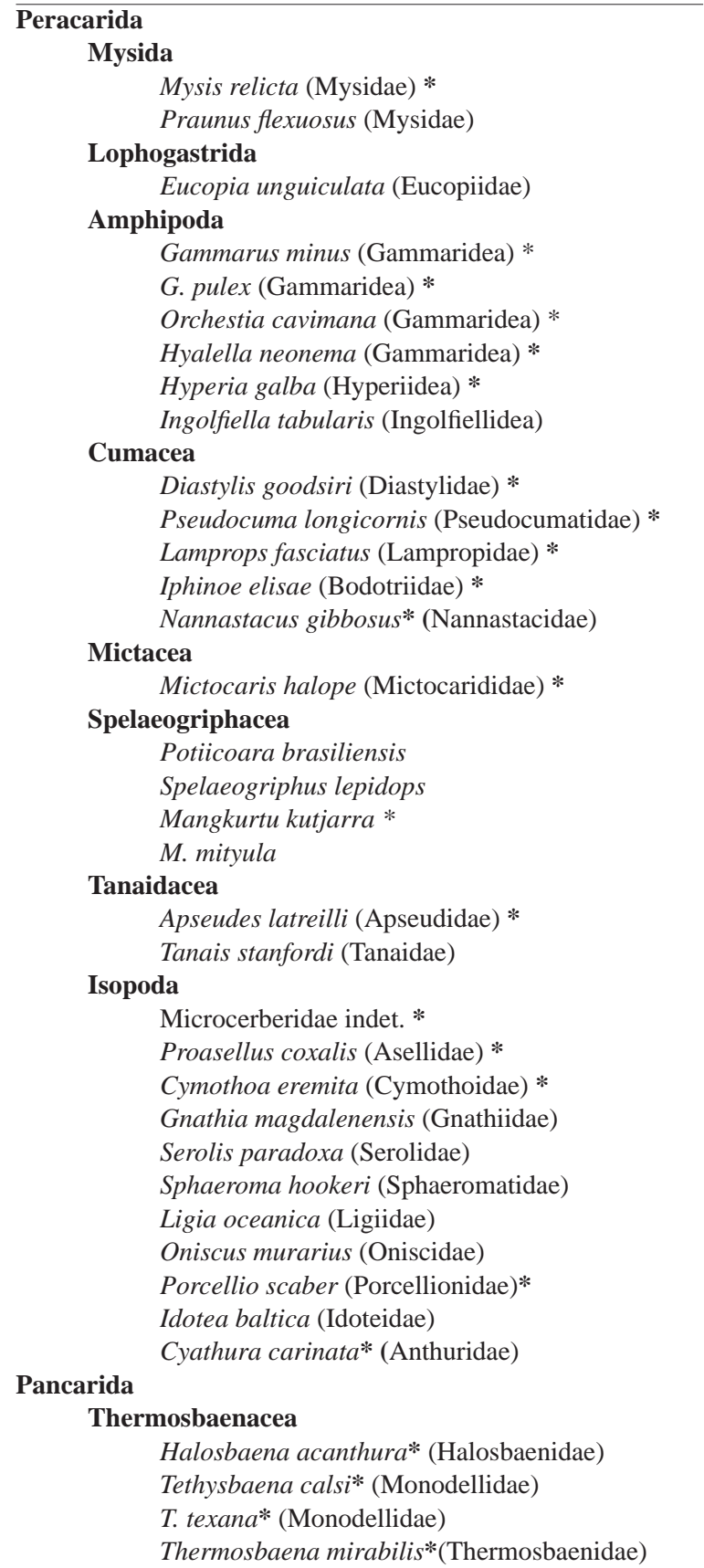

\section{Results}

Although our immediate goal was not to deal with issues of phylogenetic relationships (Schram and Hof, 1998), nonetheless, rather than present taxa in alpha- betic order, it proved useful to group our higher taxa (Watling, 1992) in some proximity to species to which they bear some relationship.

\section{Thermosbaenacea}

We examined the species Thermosbaena mirabilis, Tethysbaena texana, Tethysbaena calsi, and Halosbaena acanthura. Thermosbaena mirabilis has a pleotelson, but all other forms possess a free telson. However, the location of the anus varies to such a degree that one cannot generalize.

Bowman (1971) incorrectly reported a basal anus in Thermosbaena (Monod and Cals, 1999), while Wagner (1994) mentioned it as subterminal in location. We found that in T. mirabilis (Fig. 1.1) the anus is found in a terminal position on what is termed the pleotelson (Fig. 1.2). Ventrally one can see that the uropods insert on the posterior aspect of what could be considered the sixth pleomere, while dorsally a continuous pleotelson unit is expressed extending posterior to the attachment of the ventral uropods.

By contrast, the telson is free in Tethysbaena texana (Fig. 1.3) as well as T. calsi (Fig. 1.6), and the anus is situated subterminally in the former species on the ventral surface of a free telson (Fig. 1.4) and terminally in the latter species (Fig. 1.5), confirming Wagner (1994). This arrangement challenges Bowman's axiom that an anus "never occurs" in any (near) terminal position on a true telson. However, we note that Halosbaena acanthura displays a mid-ventral position for the anus (Fig. 1.7) on the free telson (Fig. 1.8), and this is inconsistent with the statements made by Wagner (1994) that in the thermosbaenaceans the anus is always situated subterminally, or Schminke (1976), who writes that thermosbaenaceans have a terminal anus.

\section{Mysida and Lophogastrida}

The mysidaceans are frequently allocated a basal position within Peracarida; there are two living groups, Mysida and Lophogastrida. Both groups possess a rather long and a more-or-less flattened telson that together with the uropods forms a tail fan. The long, extended pleon contains six well-developed pleomeres. The anus opens at the base of the telson (Fig. 2), which is the typical position seen in other 

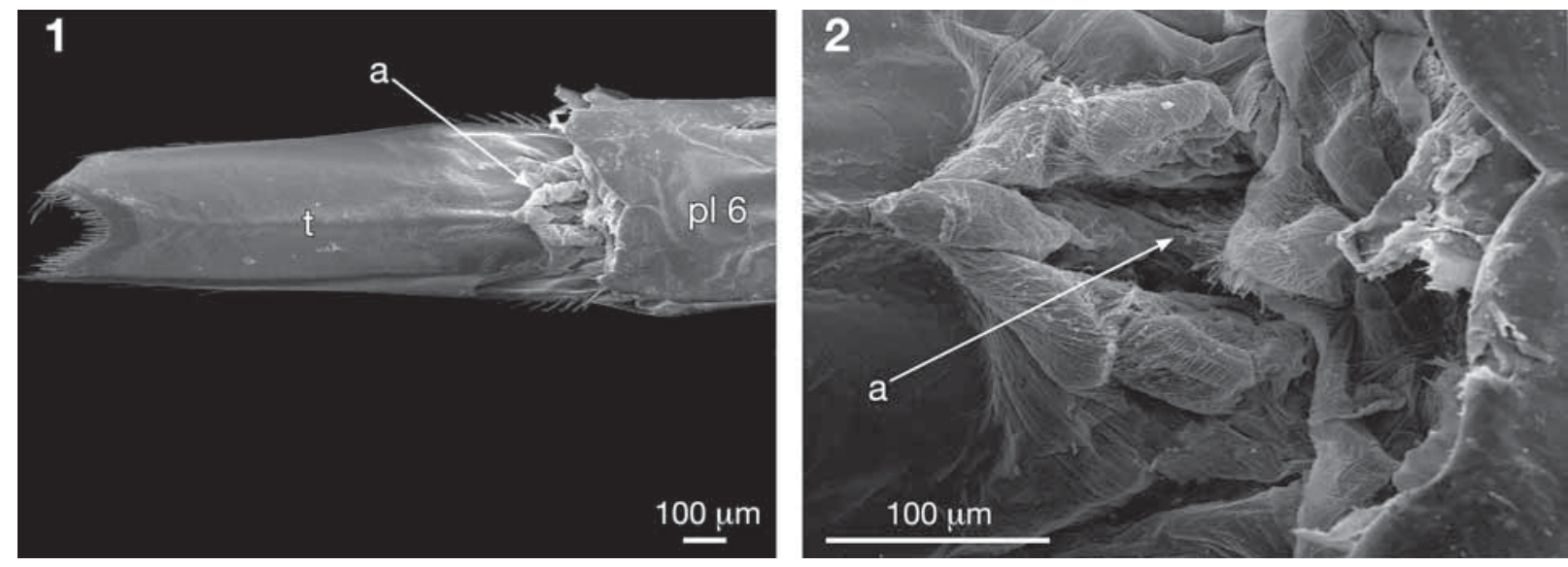

Fig. 2. Mysida (1) Mysis relicta, pleomere six and telson, ventral view, with anus opening at base of telson. (2) M. relicta, details of anus, note complex structure of folds and setose valves around anus. $\mathrm{a}=$ anus, $\mathrm{pl} 6=$ pleomere 6 , $\mathrm{t}=$ telson.

pelagic and epibenthic malacostracans with tail fans. This is also true for the extinct order Pygocephalomorpha, which is often aligned with the living mysidaceans (Schram, 1986).

The anus of the mysidans opens ventrally at the base of the very elongate separate telson (Fig. 2.1), as we confirmed in Mysis relicta and Praunus flexuosus. The anus in the former is clearly guarded by a complex series of folds and valves (Fig. 2.2). Several early investigators suggested that a seventh mesodermal somite in mysid embryos was an indica- tion of a seventh pleonal segment (Manton, 1928; Nair 1939), but any such seventh pleomere is not traceable in adult mysidans.

Interestingly, the adult lophogastrids possess a transverse furrow within the last pleonal segment, suggesting that this sixth pleomere originally consists of two components (Grüner, 1993; Schram, 1986). Examination of engrailed expression within these two groups should lend insight into the developmental patterning of the urosome region.

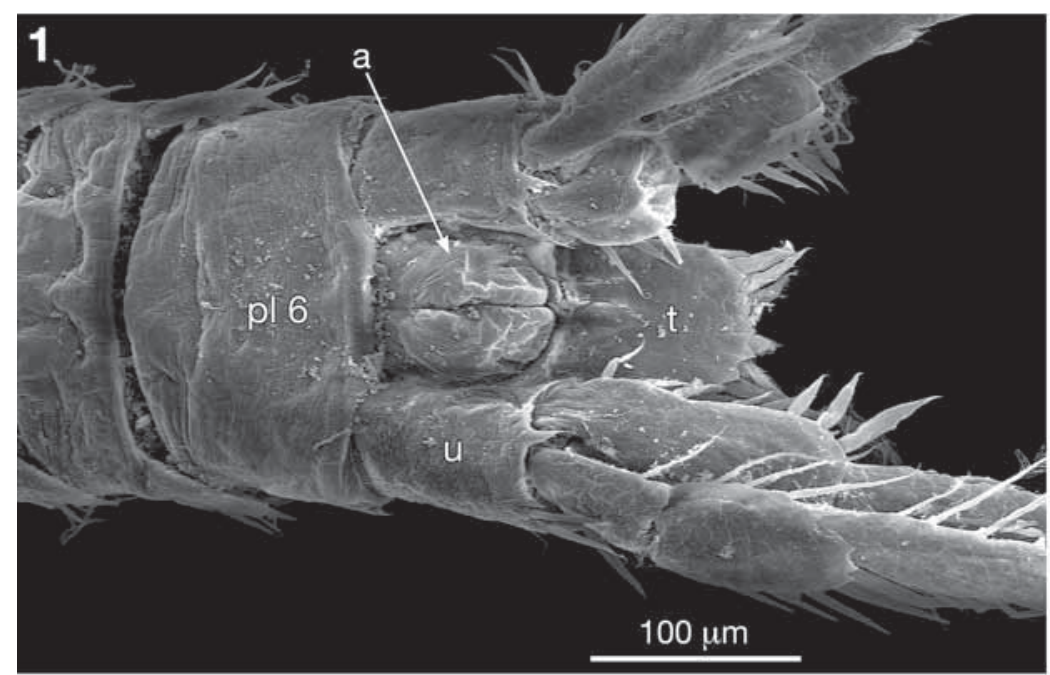

Fig. 3. Mictacea. (1) Mictocaris halope, pleomere six, telson and uropods, ventral view, with anus situated basally on telson. (2) Thetispelecaris yurikago, pleomere six, telson and part of right uropod, ventral view, with anus opening terminally on telson (modified from Ohtsuka et al., 2002). a = anus, pl 6 = pleomere 6, $\mathrm{t}=$ telson, $\mathrm{u}=$ uropod.

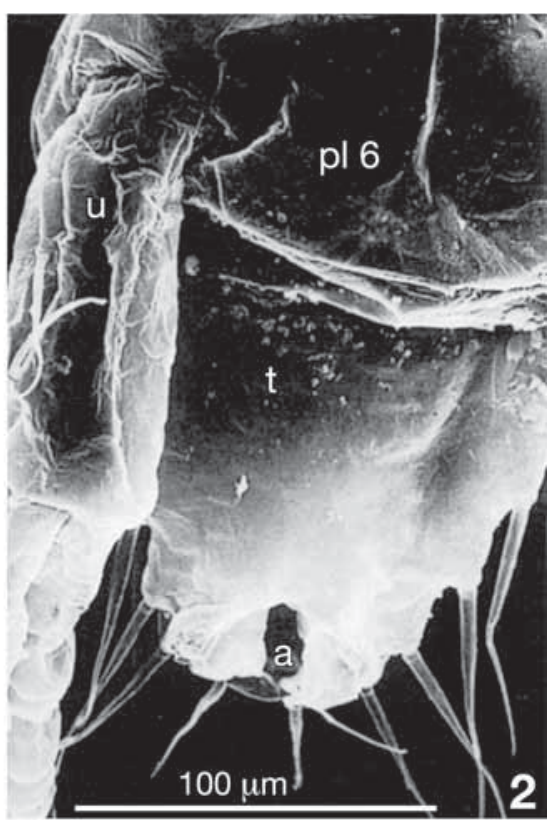




\section{Mictacea}

The mictaceans currently include two families, the Mictocarididae Bowman and Iliffe, 1985 and the Hirsutiidae Sanders et al., 1985. Their relatively recent discovery precluded their being treated in Bowman (1971). The telson of the mictaceans is free and not fused to the sixth pleonal somite. The anus of Mictocaris halope is definitely situated at the base of the telson (Fig. 3.1). However, the situation is dramatically different in Hirsutia sandersetalia. Just and Poore (1988: 488) pointed out that "in Hirsutia the anus opens ventrally at the extreme posterior end of the telson" and they drew "... attention to the fact that the two mictacean families are very different in this point”. A terminal location of the anus was also reported for Thetispelecaris yurikago (Fig. 3.2; Gutu and Iliffe, 1998; Gutu, 2001; Ohtsuka et al., 2002), a taxon that was placed in the family Hirsutiidae by Gutu (2001).
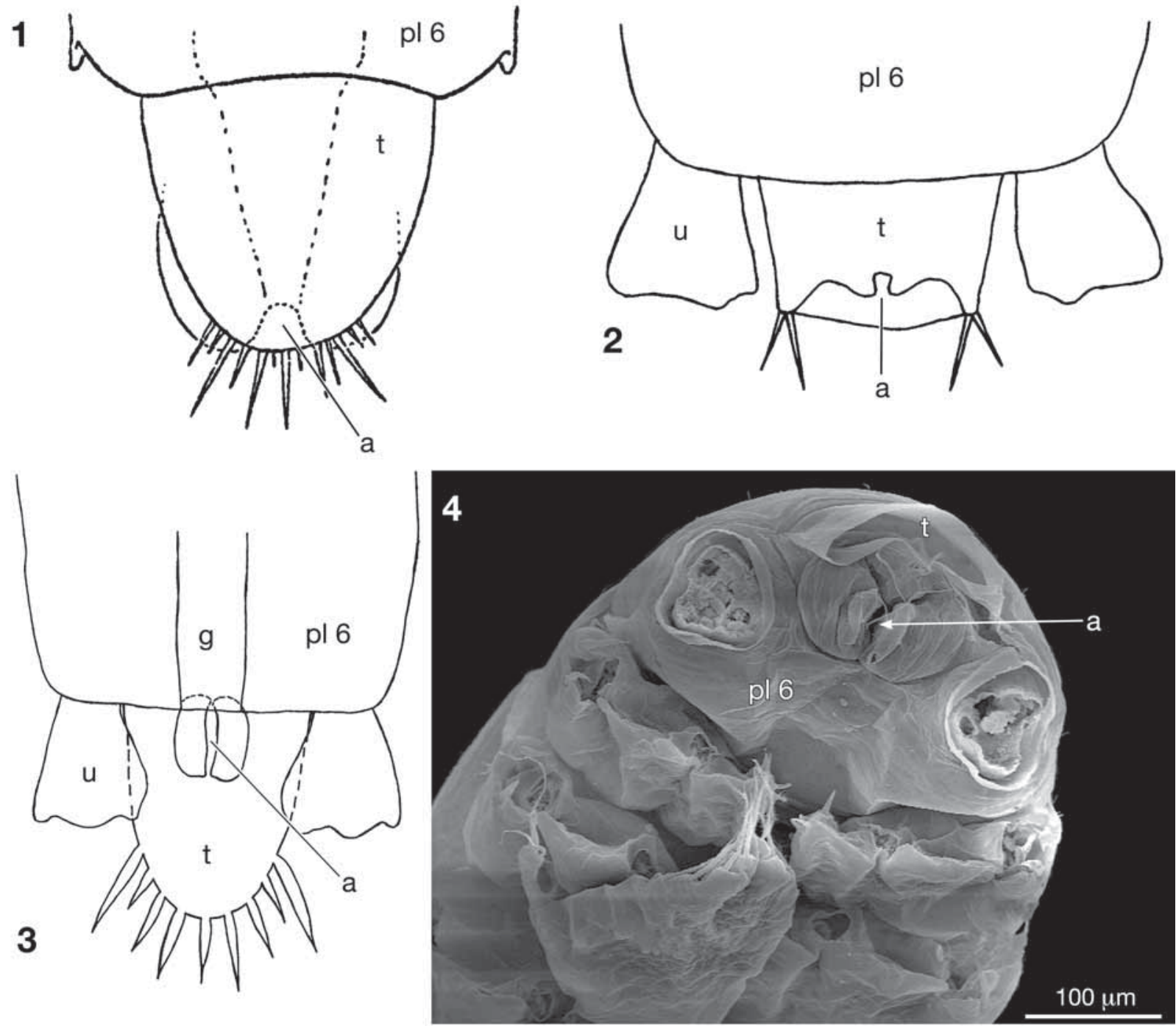

Fig. 4. Spelaeogriphacea. (1) Spelaeogriphus lepidops, pleomere six and telson, dorsal view (modified from Gordon, 1957). (2) Potiicoara brasiliensis, pleomere six and telson, base of uropods indicated, ventral view. (3) Mangkurtu mityula, pleomere six and telson, base of uropods indicated, ventral view revealing an apparent basal anus. (4) Mangkurtu kutjarra, SEM of posterior terminus, note that the distal portion of the telson has been broken off to reveal the placement of the anus posterior to the sixth pleomere between the attachment points of the uropods. $\mathrm{a}=$ anus, $\mathrm{g}=$ gut, $\mathrm{pl} 6=$ pleomere $6, \mathrm{t}=$ telson, $\mathrm{u}=$ uropod. 


\section{Spelaeogriphacea}

In Spelaeogriphacea, we also observed a degree of variability concerning the anatomy of the body terminus. The telson is always separated from the last pleomere. However, Bowman (1971), in taking up Spelaeogriphus lepidops, and uncertain as to the exact anatomical location, construed a terminal position on the telson for the anus based on his interpretation of the drawings of Gordon (1957). Schminke (1976) observed a terminal anus in $S$. lepidops. Bowman, in fact, declared that such a condition was “... unusual for a malacostracan" (Bowman 1971: 171). The drawing of Spelaeogriphus lepidops made by Gordon, however, appears to us to depict a subterminal position for the anus, and our examination of specimens of this species confirms this (Fig. 4.1). In Potiicoara brasiliensis, however, the anus clearly opens on the posterior aspect of the telson (Fig. 4.2). The Australian species, Mangkurtu mityula, as originally described appeared to have an anus located basally on the telson (Fig. 4.3). Nevertheless, material we have at hand of both $M$. mityula and $M$. kutjarra clearly reveals in both species an anus situated on the posterior surface of the sixth pleomere with the distinct flap-like telson situated dorsal to it (Fig. 4.4)

\section{Cumacea}

Though the general body habitus of Cumacea is very consistent across members of the group (bulbous cephalothorax, long and thin pleon; Fig. 5.5), they display some striking variations regarding the body terminus. There are some eight families of cumaceans (Grüner, 1993; Schram, 1986), for which the phylogenetic relationships are just beginning to become clear (Haye et al., 2004). What had been thought to be two clades of families with and without a free telson, to be appears a paraphyletic stem composed of the families with a free telson, and a terminal clade with families possessing a so-called pleotelson. Bowman believed that certain cumacean families do not have a telson; while for Schminke all cumaceans have a telson but that in three of the families it is fused with the last pleomere.

We observed that five of the eight cumacean families (Lampropidae, Pseudocumatidae, Ceratocumatidae, Gynodiastylidae and Diastylidae) possess a free telson of varying size and form, and the anus is located in different positions on these telson. In Diastylis goodsiri (Fig. 5.1), the anus is located basally on a long telson. Pseudocuma longicornis (Figs. 5.2, 5.3) carries a basal anus on a shorter rounded telson. However, Lamprops fasciatus (Fig. 5.4) has the anus located somewhat more posteriorly. Furthermore, the gynodiastylid, Allodiastylis cretata (Fig. 5.5), displays a terminal anus on the telson. Finally, in the ceratocumatids, while the telson is very small and rounded, and separated from pleomere six (Kaestner, 1993; Bishop, 1980), the exact position of the anus is not clear.

The three remaining families of cumaceans (Bodotriidae, Leuconidae, Nannastacidae) are traditionally said to have a pleotelson (Schminke, 1976; Schram, 1986; Grüner 1993). However, Bowman (1971) disagreed with this characterization and concluded that a telson in these groups is simply lacking. Indeed, based on our observations we would tend to agree that the existence of the telsonic portion of a putative pleotelson is questionable in several species. Certainly, the posterior terminus of these cumaceans differs in appearance from a typical pleotelson, which would be a structure that protrudes posteriorly past the onset of the uropods, as in Thermosbaena mirabilis (see above) or in many isopods (see below). In the genus Campylaspis (Fig. 5.6) the last pleonal segment appears to be without any fused telson component. However, in other cumaceans, the case is somewhat ambiguous. In the bodotriid, Iphinoe elisae, and the nannastacid, Nannastacus gibbosus, there appear to be a variously developed shelves located dorsal to the anus; if so, such an arrangement is reminiscent of what occurs in amphipods (see below). In I. elisae, this shelf (Fig. 5.7), which is not separated from the sixth pleonal segment, protrudes posteriorly over the anus. In $N$. gibbosus (Figs. 5.8), a small, short, dorsal protrusion or flap is found above the anus. While the nature of the protrusions in these families is not clear, nevertheless, the anus in these taxa lies in a comparatively terminal location. In the leuconid, Leucon bacescui, (Fig. 5.9), however, a broadly triangular, posteriorly directed extension of the pleonal unit would seem to represent a true pleotelson.

\section{Tanaidacea}

The living tanaidaceans have one important feature in common: they all lack a free telson. In contrast, the extinct Anthracocaridomorpha, which is cur- 

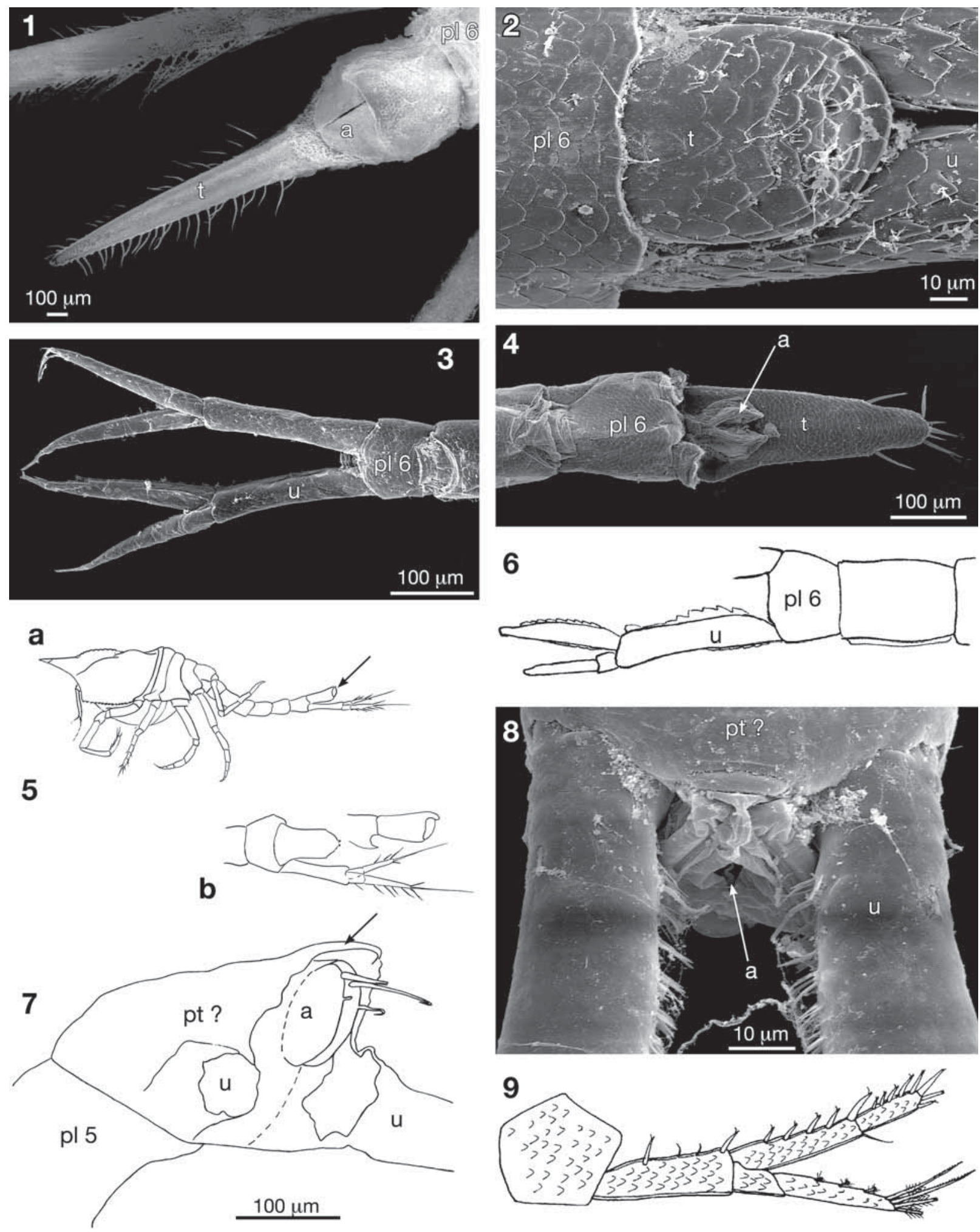

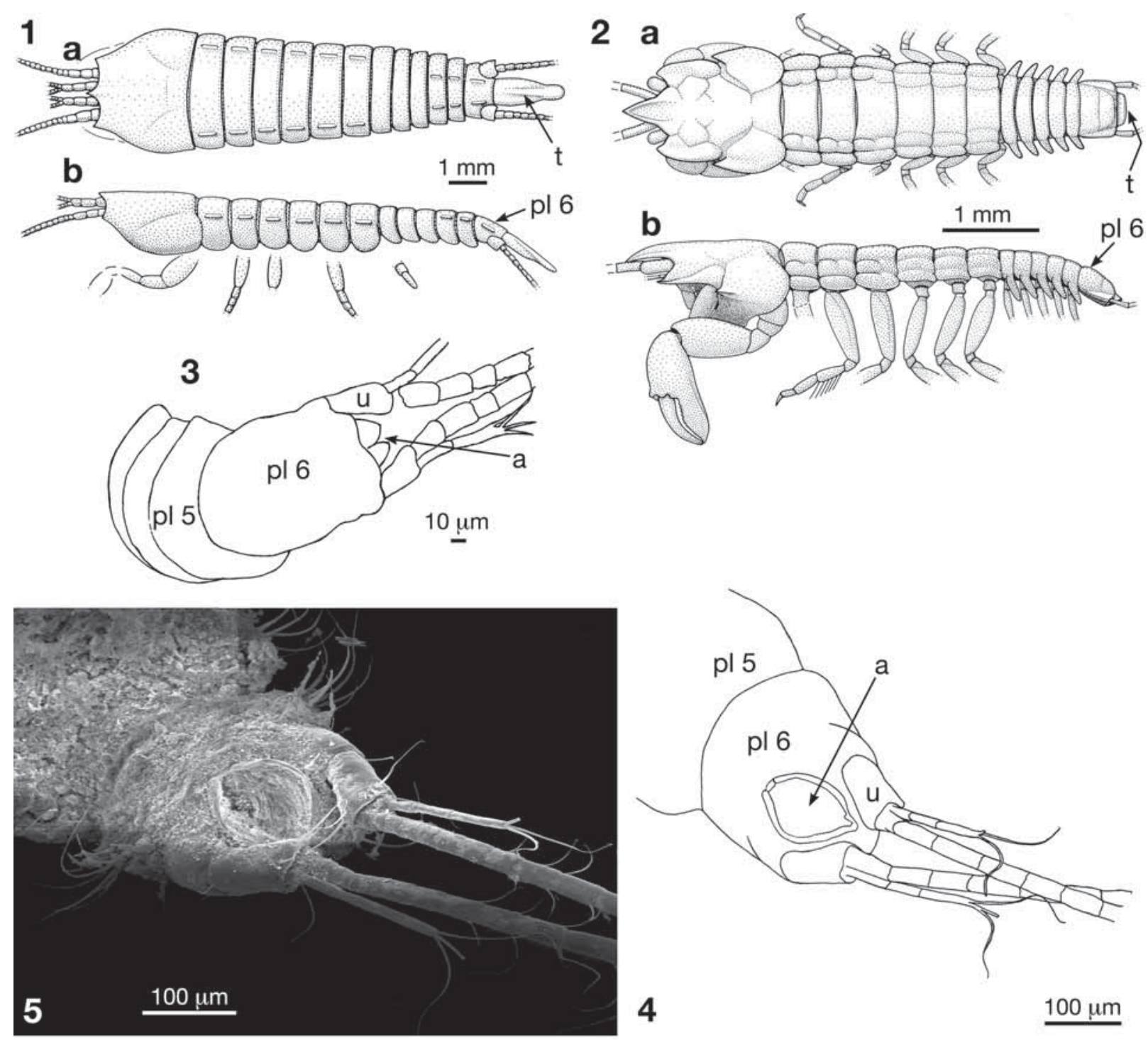

Fig. 6. Tanaidacea. (1) Anthracocaris scotica, habitus, dorsal (a) and lateral (b) views, extinct form with long flat telson; note that last pleomere (six) longer than any of the preceding ones (arrow) (from Schram et al., 1986). (2) Ophtalmapseudes rhenanus, habitus, dorsal (a) and lateral (b) views, extinct species with very short telson; note that sixth pleomere differs in length from preceding pleomeres (arrow) (from Schram et al., 1986). (3) Apseudes latreilli, pleomeres three to six, and part of uropods (right uropod broken), dorsal view; note anal valves projecting beyond hind margin of the last body unit. (4 and 5) A. latreilli, pleomere five and last body unit, ventral view, with subterminal anus. $\mathrm{a}=$ anus, pl $5=$ pleomere 5 , pl $6=$ pleomere $6, \mathrm{t}=$ telson, $\mathrm{u}=$ uropod.

Fig. 5. Cumacea. (1) Diastylis goodsiri, pleomere six and elongate telson, ventral view; shape of telson typical for Diastylidae. (2) Pseudocuma longicornis, telson, dorsal view, with small rounded telson. (3) P. longicornis, pleomere six, telson and uropods, ventral view, with anus located basally on telson. (4) Lamprops fasciatus, pleomere six and telson, ventral view. (5a) Allodiastylis cretata, habitus (lateral view), with anus in terminal position on telson (arrow); (5b) A. cretata, caudal area with pleomere six, left uropod, and a long telson with terminal anus (modified from Gerken, 2001). (6) Campylaspis sp., pleomere six, without telson? and right uropod, dorsal view (modified from Zimmer, 1980). (7) Iphinoe elisae, pleomere five, last body unit and left uropod (partly removed), lateral view, with anus located beneath dorsal flap. (8) Nannastacus gibbosus, last body joint and uropods, ventral view, revealing small dorsal flap (arrow; telson rudiment?) that is not separated from the last body joint. (9) Leucon bacescui, last body unit (= pleotelson) and left uropod, dorsal view (from Petrescu, 1994). a = anus, pl 6 = pleomere 6, pt = pleotelson, $\mathrm{t}=$ telson (free), $\mathrm{u}=$ uropod. 
rently comprised of two families and four genera (Schram et al., 1986; Gutu and Sieg, 1999), carried a separated telson. In the Lower Carboniferous species, Anthracocaris scotica, the telson is rather long (Fig. 6.1); in the Permian form, Ophthalmapseudes rhenanus, it is rather short (Fig. 6.2); between these is the Upper Carboniferous (Pennsylvanian) Eucryptocaris ascherorum, with a telson intermediate in length (Schram et al., 1986).

Some differences of opinion exist concerning the urosome of the recent tanaidaceans. The majority maintain that the posterior part of the pleon represents a pleotelson (Schram, 1986). Nevertheless, Bowman (1971) suggested that the last 'segment' of recent Tanaidacea should be interpreted simply as the sixth pleonal, or anal, somite, i.e., the tanaidaceans lack any telson component. We noted that the anus displays a distinct posterior ventral orientation, as in Apseudes latreilli (Figs. 6.3-5). This arrangement is similar to that seen in Ophthalmapseudes rhenanus, a taxon characterized by the possession of both six pleomeres, and a short free telson.

\section{Isopoda}

The majority of isopods possess a pleotelson formed by the fusion of the telson and one to several pleomeres. A suture is often visible between the sixth pleomere and the telson, e.g., in young stages of many Asellidae, which possess a pleotelson in the adult stage (see Roman and Dalens, 1999).

Most isopods have the anus more or less situated on pleomere 6, as a part of the pleotelson. In the species we examined, the telson is at least fused to the sixth pleonal segment, but often a fusion with even more anterior pleomeres has taken place, e.g., Sphaeroma hookeri or Idotea baltica, with the five sets of pleopods partly embedded in the pleonal respiratory chamber (Atemkammer). The arrangement of the sixth pleomere relative to the telson is nicely illustrated by the terrestrial isopod Porcellio scaber (Oniscidea), where we can see a suture separating the telsonic part from the pleomeral part in ventral view (Fig. 7.1). The dorsal equivalent of this suture is visible in young specimens. The anus proper is located at a mid-ventral position on the pleotelson anterior to the suture between the telsonic part and pleomere 6. The uropods insert rather distally, but generally an out-growth projects posteriorly between the uropods representing the remnants of the former telson. However, while the presence of a pleotelson is not doubted for most isopods, nevertheless, the variability can be complex.

The asellote, Proasellus coxalis, possesses a pleon with a highly fused array of segments (Fig. 7.2). Only the first and second pleomeres are free, a condition peculiar to Asellota. A rather small telson is incorporated into this fused unit, although we noted a slight suture between the fused portion of the pleon (pleomeres three to six) and the distal extension (putative telsonic part). The asellote anus is located at the level of the insertion of the uropods on the putative pleonal part of the pleotelson (Fig. 7.3). This condition corresponds to what we see on an undetermined species of Microcerberus we examined, but there too the fusion pattern of pleomeres is very complex. Pleomeres one and two are free segments and the remaining four segments are fused to one terminal unit about as long as the preceding free pleomeres. However, there is no extension of the pleon reaching further posterior than the onset of the uropods. The anus lies between the uropods (Fig. 7.4), and hence there seems to be no portion attributable to a telson (Fig. 7.5). The small vestige of the telson noted in Proasellus coxalis is possibly equivalent to that which is completely reduced in Microcerberus. This may be connected with the interstitial life style of Microcerberus.

Fig. 7. Isopoda. (1) Porcellio scaber, pleotelson, uropods removed, ventral view; note ventral suture separating putative telson part of pleotelson; anus apparently on pleonal part of the pleotelson. (2 and 3) Proasellus coxalis, pleotelson and right uropod, ventral view. Though there is a complex fusion within the pleon of this species, a suture towards the dorsal out-growth was seen in some specimens (not shown). The anus does not belong to the out-growth (putative telsonic part) but rather to the pleonal part of the pleotelson. (4 and 5) Microcerberus sp., pleomere two, fused pleomeres three to six and uropods (gut indicated), ventral view; note that hind margin of terminal unit is truncated, with anus opening terminally between uropods (indicating possibly an absent telson in species of this genus). (6 and 7) Cyathura carinata, pleon (gut indicated), ventral view, with pleomeres one to five fused whereas sixth pleomere and telson are free; note anus on sixth pleomere. (7) Phreatoicopsis terricola, last body unit and right uropod (posterior and lateral view), with anus opening terminally (= truncated pleotelson?) (from Wilson and Keable, 2002). $\mathrm{a}=$ anus, g = gut, p 1-5 = fused first five pleomeres, pt = pleotelson, $\mathrm{t}$ = telson, $\mathrm{u}=$ uropod. 

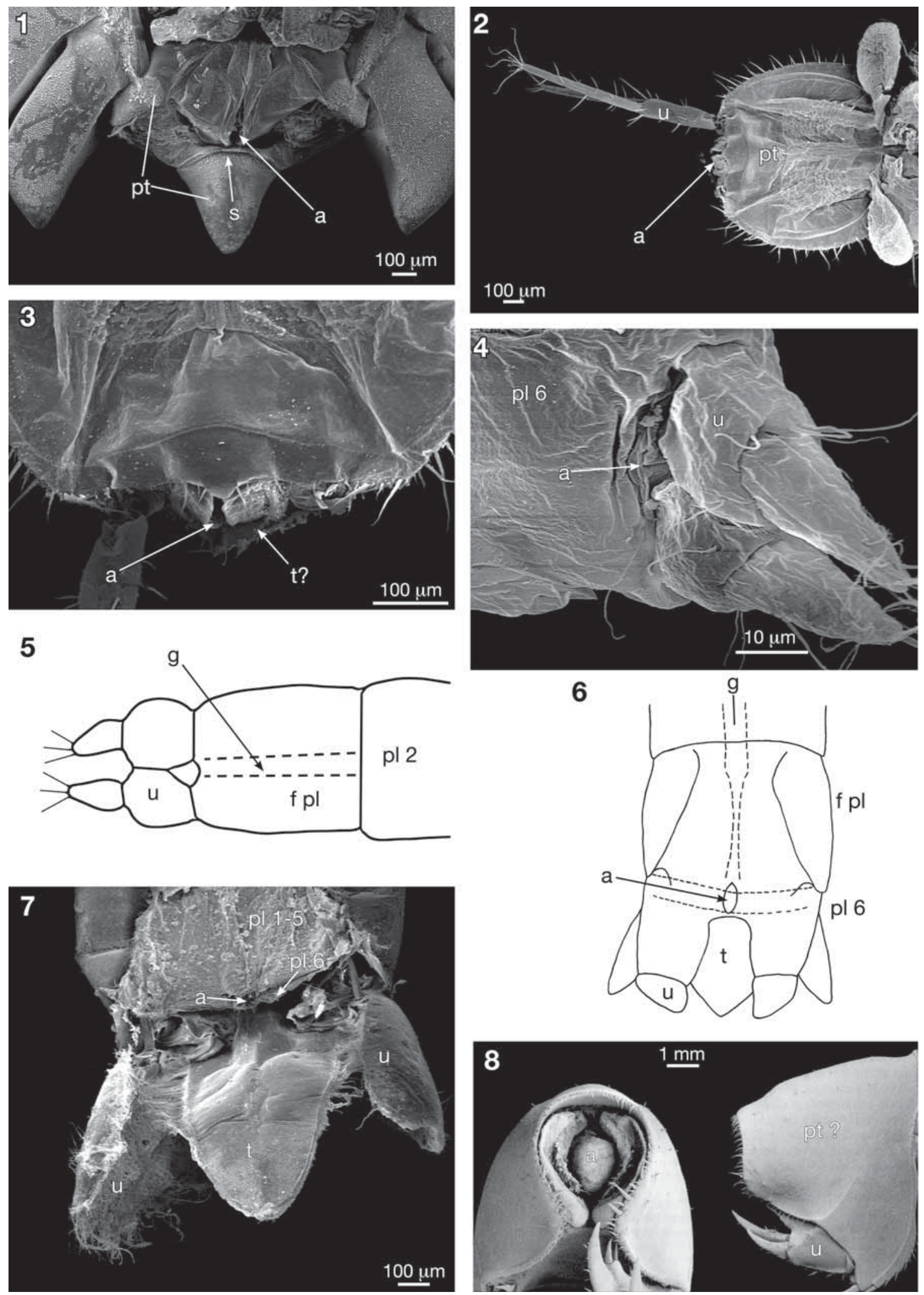
In the anthuridean, Cyathura carinata, pleomeres one to five are fused to each other (Fig. 7.6). No distinct pleomeres are present, while in contrast the portion that corresponds to pleomere six bears the uropods. The free telson is flat and together with the uropods comprises a tail fan (Fig. 7.7).

Another anatomically interesting arrangement occurs in Phreatoicidea, an ancient suborder (Schram, 1986; Wilson and Keable, 2002). For example, Phreatoicopsis sp., exhibits a characteristic form of the pleotelson, which is circular in posterior view and exhibits a truncate posterior margin with the anus shielded within a recess (Fig. 7.8). However, since the anus lays some distance posterior to the uropod insertions, this terminal unit is considered a pleotelson (Erhard, 1998).
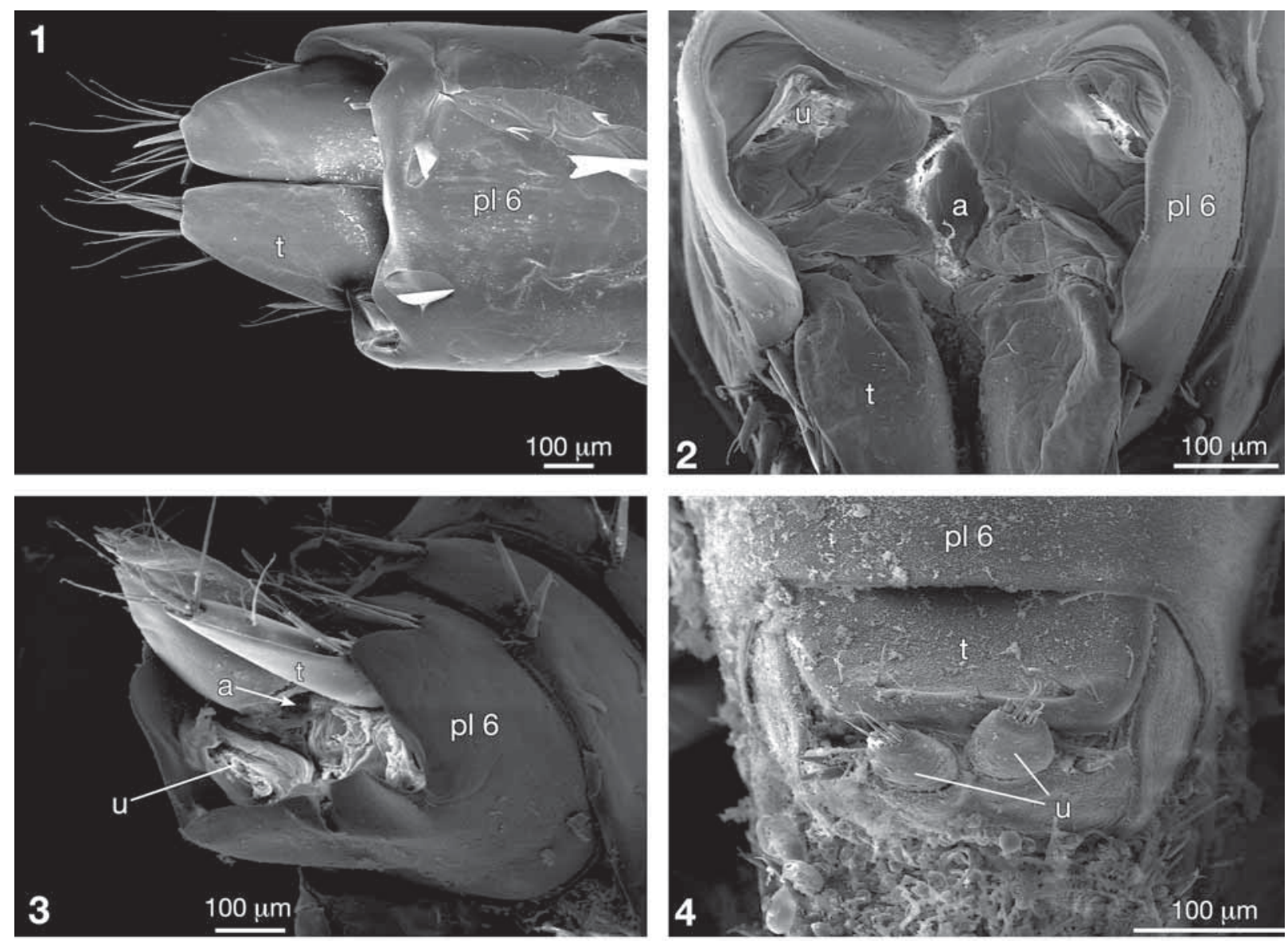

Fig. 8. Amphipoda. (1) Gammarus minus, pleomere six and cleft telson (ventral view). (2 and 3) Gammarus minus, dorsal and posterior view on pleomere six (uropods removed), with anus opening terminally on pleomere six; note the lack of coalescence of anus with telson. (4) Hyallela neonema, telson appears as a single fused shelf, anus exiting on posterior side of sixth pleomere hidden between the third uropods. $\mathrm{a}=$ anus, $\mathrm{pl} 6=$ pleomere $6, \mathrm{t}=$ telson, $\mathrm{u}=$ uropod points of attachment. 
also Bowman, 1971). For example, we noted in Gammarus minus the anus appears on the posterior surface of the sixth pleomere ventral to the telson. An identical arrangement occurs in Hyalella neonema (Fig. 8.4), which has an uncleft telson. Furthermore, the embryonic generation of this pattern presents some unusual features (see below).

This gammarid pattern holds for other amphipod groups as well. The last pleomere in the hyperiids is the product of the fusion of the fifth and sixth pleonal somites. This is easily recognizable due to the two pairs of (uropod) appendages on this segment, but the position of the anus vis-a-vis the telson in Hyperiidea does not differ with regard to that seen in other amphipods. In the minute Ingolfiellidea, the anus is situated ventral to the telson on the posterior surface of pleomere six (Siewing, 1963). Caprellids possess a highly reduced pleon, and therefore they were not incorporated into this study.

\section{Embryology}

Our morphological comparisons show that in many cases we can unambiguously identify a pleotelson, a true telson, and of course, directly observe the location of the anus. Problems arise when it appears that the telson is completely fused to a sixth pleomere bearing a terminal anus and terminal uropods. In the latter case, we are unable to determine whether the telson was ever present at all. Only a consideration of development stages can provide information to answer that question.

All Pera- and Pancarida possess a direct mode of development. In both groups, most of the post-cephalic segments originate from teloblasts (ectoteloblasts and mesoteloblasts), which bud off their descendant cells in an anterior to posterior direction (Richter and Scholtz, 2001). In this process, a grid like pattern forms on the germ band of peracarids. However, as noted earlier, the amphipods lack ectoteloblasts. In this respect, amphipods are very special. Nevertheless, they show the mentioned grid-like pattern of longitudinal and transversal cell rows in the embryo (Scholtz 1990, 2000).

The proctodaeum can occur in a variety of places. In most species of peracarids investigated so far, the proctodaeum is initiated a short distance behind the row of ectoteloblasts, e.g., two to three cell rows behind the ectoteloblasts in Hemimysis lamornae (Manton, 1928; Nair, 1939) and in several species of Isopoda (Nair, 1956; McMurrich, 1895; Strömberg, 1972). In amphipods, the initial proctodaeal invagination occurs several cell rows behind those of the last pleonal segment (Weygoldt, 1958, Ungerer and Wolff, 2005). In tanaidaceans (Scholl, 1963) and the isopod Idotea (Strömberg, 1965), the anus forms immediately behind the teloblasts. In contrast, the cumaceans and Thermosbaena mirabilis offer a quite extended area of cell proliferation behind the teloblasts, and the proctodaeum appears at the very tip of this region (Dohrn, 1870; Zilch, 1974, 1975).

The telson in Recent Tanaidacea is probably completely reduced. In his investigations concerning the development of Heterotanais oerstedi, Scholl (1963) recognized a peculiarity concerning the structure of the forming proctodaeum. He indicated that the proctodaeum of tanaidaceans, which forms immediately behind the ectoteloblasts, drags many cells into the interior of the developing embryo. Before the formation of the proctodaeum started, these cells were located posterior to the area of invagination. In other words, these are cells of the putative telson Anlage in the early embryo. During the ontogeny of the anus, these cells are involved in hindgut formation and therefore do not contribute to the formation of a telson of the adult. In contrast to the dorsal wall of the forming proctodaeum, the ventral wall of the tanaidacean anus seems to form from only few (blastoderm) cells that divide repeatedly. Because of this, the ventral side of the proctodaeum features a different type of cell. The described process might correspond to a reduction in size of the posterior-most part of the germ band (telson Anlage), and the process might depict a loss of the adult telson. Unfortunately, Scholl did not discuss comprehensively the fate of the ectoderm that is located posterior to the ectoteloblasts.

We encounter a special case in Orchestia cavimana. The pleomeres are initially specified by a grid-like alignment of ectodermal cells (Fig. 9.1; Ungerer and Wolff, 2005), which is especially evident posteriorly. In this case, clear delineation of seven segmental units can be detected, and a little later, an eighth unit marks the terminus of the germ band (Fig. 9.3). We observed that the proctodaeal invagination occurs in this eighth unit (Fig. 9.4), which might then be iden- 

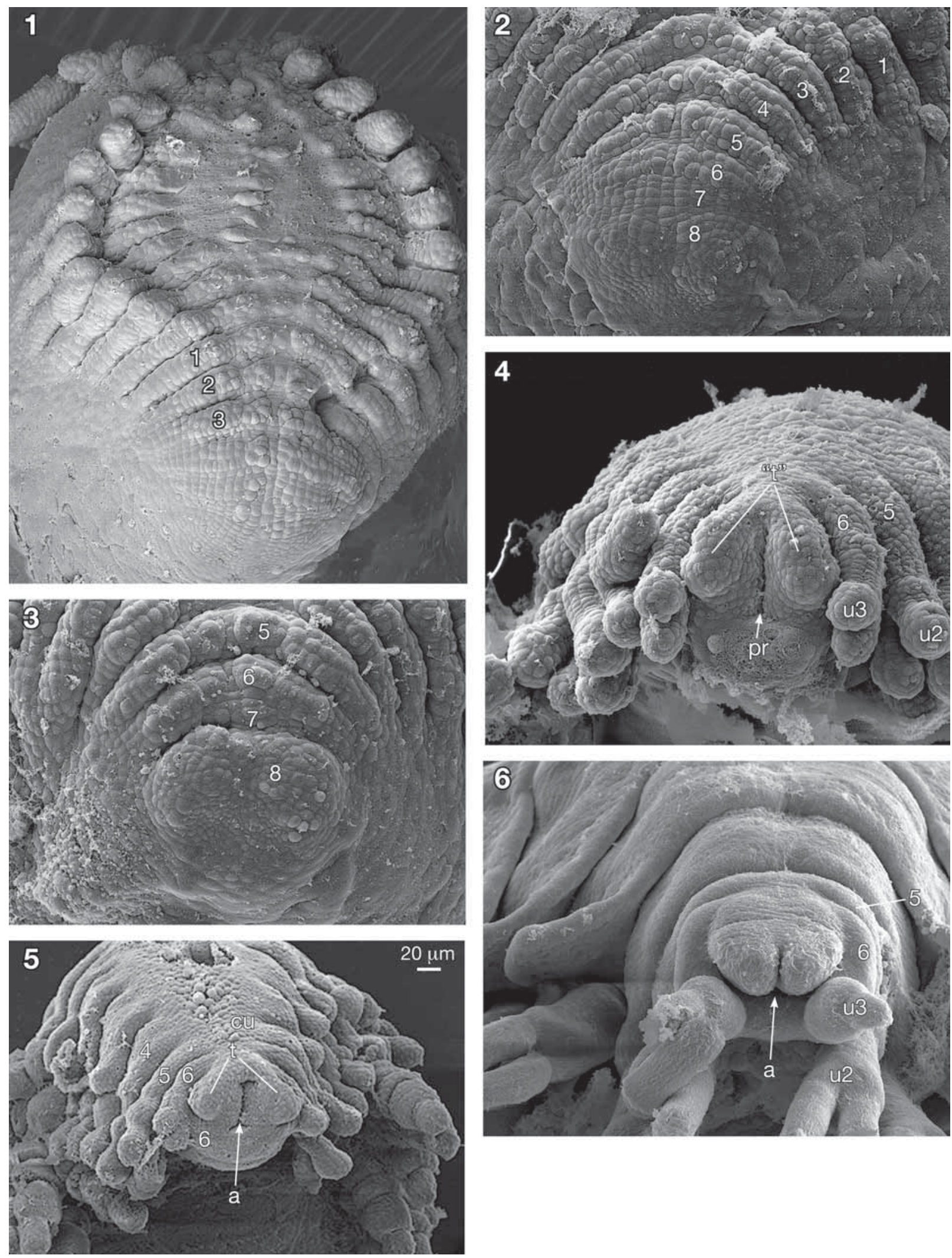
tified as a putative telson. However, shortly after the proctodaeum begins to invaginate, two latero-ventral swellings begin to form (Fig. 9.5) on either side of the putative anus. As development progresses, the distinctness of the tissues of the eighth unit fades as the anus and paired lobes swell, and the seventh pleomere unit appears to shrink. Consequently, the anus comes to open on the posterior aspect of the sixth pleomere. Meanwhile, the separate paired lobes (Fig. 9.5) continue to enlarge, project posteriorly, and migrate to a dorsal position (Fig. 9.6) relative to the anus. In Orchestia cavimana, these two lobes remain separated and form what is generally termed the cleft telson. Our concurrent observation of the development of Hyalella azteca, reveals a similar sequence of events, except in this species the paired lobes come together in the area dorsal to the anus and fuse to form a single shelf-like structure.

It would appear, from our interpretation, that the structure we commonly refer to as a telson in amphipods in fact develops rather differently from those telsons we encounter in other groups of malacostracans such as the mysidaceans (see discussion below). The amphipod lobes seem to be akin to caudal rami in their manner of appearance.

\section{Discussion}

Our examination of a selected sample of pera- and pancarid eumalacostracans suggests that the nature of the body terminus in these groups is quite variable (Table 2). The vast majority of pera- and pancarids have the classic arrangement of a telson often bearing a basal anus. Actual instances of a real and unambiguous pleotelson are rare (Thermosbaena mirabilis, some cumaceans, and isopods). Moreover, we cannot say that a free telson always carries an anus at its base, since a terminal anus on a telson is encountered almost as often, e.g., species of Spelaeogriphacea,
Thermosbaenacea, Mictacea, and some Cumacea. Nor can we easily dispose of matters by assuming there is always either a telson or a pleotelson. In at least two instances, we might conclude that a telson is completely absent, i.e., the cumacean, Campylaspis, and possibly in the amphipods and living tanaidaceans. In fact, it would appear that by automatically invoking the classic assumptions about malacostracan body plans one denigrates the wide array of variation evident in this area of the body.

The presence of a telson in crustaceans is often taken as a given. For example, Grüner declared that in all instances the body terminus of crustaceans is formed by a telson (Grüner, 1993: 449). Sharov (1966) and Bowman (1971) tried to break out of these constraints by positing two non-homologous body terminations in Crustacea: 1) an anal somite having caudal rami and a terminal anus, and 2) a telson without caudal rami and the anus opening on the antero-ventral surface. Groups like Leptostraca, Anostraca, and Notostraca (Triops) would lack a true telson since they possess a terminal anus and caudal rami, which Bowman suggested as analogues of the uropods.

In fact, the Notostraca provide an excellent example to illustrate non-homologous body terminations in crustaceans. The terminal somite in notostracans is traditionally referred to as 'telson'. However, this last segment bears a terminal anus; hence, it should be regarded as an anal somite without a true telson. The anal somite can be covered by a supra-anal plate (Lepidurus), which obviously is an out-growth of the terminal abdominal tergite and may not be homologous to caudal plates in other taxa (Fig. 10). These distinctions between non-homologous structures are essential not only for phylogenetic inferences, but also for our understanding of evolutionary processes in general.

However, our observations also show that there are instances when a true telson can bear a terminal

Fig. 9. Development of proctodaeum in Orchestia cavimana; 1-3 with venter of animal facing up, 4-6 with venter of animal facing down. (1) Late germinal disc stage, with complete series of segments in thorax and seven segments in pleon. (2) Somewhat more advanced stage than 1, with appearance of pleonal unit 8. (3) Caudal papilla forming, note paired swellings on eighth unit and reduction of seventh unit. (4) Segmental boundaries not yet complete dorsally, initial proctodaeal invagination beginning between so-called paired 'telson' Anlage, seventh unit disappeared. (5) Anal opening complete, 'telson’ Anlagen enlarged, remaining tissues of eighth unit reduced. (6) Anus comes to rest on pleomere six, 'telson' Anlagen have migrate to mid-dorsal position above anus and fuse proximally. 1-8 = somite Anlagen of pleon, $\mathrm{a}=$ anus, $\mathrm{cu}=$ caudal unit, $\mathrm{pr}=$ proctodeum, ' $\mathrm{t}$ ' = so-called telson Anlagen, or caudal rami, $\mathrm{u} 2=$ limb bud of uropod 2, u3 = limb bud of uropod 3. 
anus. While we agree with Schminke (1976) that the bathynellaceans are a critical group in discerning patterns of morphologic variation in the body terminus, we believe they are unique in many respects and deserve detailed investigation in their own right. Not perhaps without reason did Serban (1972) view the bathynellaceans as so peculiar, their morphology so singular, as to warrant creation of a separate superorder, Podophalocarida.

Makarov (1978) suggested that the distinct caudal region (tail fan) had been formed in the ancestral group of Malacostraca and was radically changed in its structure only in crawling forms. If so, the typical malacostracan tail fan as seen in peracarid taxa like mysids and lophogastrids, composed of the limbs of the last pleomere and the telson, would be the plesiomorphic character state. Consequently, the basal position of the anus on the long and free telson would correspond to the ground pattern of the tail fan (Brusca and Wilson, 1991; Wägele, 1989). A shift towards a posterior position for the anus might then indicate changes that reflect habitat adaptation in certain crawling forms.

On the other hand, a shift of the anus could have taken place just as well from a posterior to an anterior position, a hypothesis that would reverse the sequence of events of the standard scenario. In such a scenario, a crawling, in-benthic form with a terminal anus would be primitive, and the pelagic, epibenthic habit would be derived.

Bowman's acceptance of only two character states, the presence of a terminal anus on a telson cannot be considered as an unusual situation for malacostracans without further rigorous analysis (Table 2).

The existence of a pleotelson in the Tanaidacea is ambiguous. No recent species with a separate telson are known; only the extinct forms possessed a distinct telson. In those fossils, the last pleomere is almost twice as long as the preceding pleomeres. This length is comparable to what is noted in the recent Tanaidacea.

Tanaidacea are adapted to a tube-dwelling life style. Only males leave their tubes to search for a mate (Bückle-Ramirez, 1965; Johnson, 1982). The reduction of the tail fan might reflect that it was not useful in the tube-dwelling habitat. This loss could have taken place by means of paedomorphosis, i.e., the telson does not enlarge during development but becomes vestigial - as in the early embryo. The original tail fan in Tanaidacea might have resembled the plesiomorphic eumalacostracan tail fan postulated by Makarov (1978). The fossil tanaidacean, Anthracocaris scotica, possessed a prominent telson and might support such a scenario. At this point, the main question is whether the loss of the tail fan was the consequence of a fusion of the telson and the last pleomere, or whether the telson was simply lost.

Several points hint at the latter option, i.e., a loss of the telson. Scholl's description concerning the formation of the hindgut in Heterotanais oerstedi indicates that a relatively large area of the posterior ectoderm cells (telsonic ectoderm?) is dragged into the infolding proctodaeum (Scholl, 1963). Therefore, this telsonic ectoderm does not contribute to the external tissues of the last body unit (whatever it is).

Furthermore, not only the terminal position of the uropods in adults of many tanaidaceans, but also the rounded solid margin of the last body unit (comparable to preceding pleonal segments) hints at a complete reduction of the telson and not a fusion of it to pleomere six. The terminal position of the anus also points to this interpretation. In the tanaidacean Heterotanais oerstedi, for example, the proctodaeum forms directly behind the ectoteloblasts (Scholl, 1963), and thus a terminal anal opening in the adult does not support a fusion of pleomere six and the telson. If such a fusion were to have taken place in Heterotanais, then the proctodeal Anlage must have migrated posteriad during ontogenesis. However, such a posteriorly directed shift of the initial proctodaeal invagination has not been reported for any other peracarid embryo (Dohrn, 1870; McMurrich, 1895; Manton, 1928; Nair, 1939; Scholl, 1963; Strömberg, 1972).

Concerning the Isopoda, Bowman (1971: 172) stated: "The telson is fused with the last $\left(6^{\text {th }}\right)$ abdominal somite, forming a pleotelson, ... . The anus opens subterminally on the pleotelson (almost terminally in some Asellota), which bears a pair of uropods.” Indeed, the presence of a pleotelson generally is not doubted for most species of isopods.

However, we believe that Bowman overlooked some relevant information. The phrase, almost terminally, does not describe the condition seen in some isopods. In Microcerberidae (Asellota) and Phreatoicopsis sp. (Phreatoicidea), the anus is terminal (see Figs. 7.4 and 7.8). In regards to the former, it is critical to note: 1) the terminal uropods, 2) the length of 
Table 2. Summary of the nature of the body terminus (urosome) and location of the anus. as = anal somite, $\mathrm{b}=\mathrm{basal}, \mathrm{cr}=\mathrm{caudal}$ rami, $\mathrm{m}-\mathrm{v}=$ mid-ventral, $\mathrm{pt}=$ pleotelson, $\mathrm{s}-\mathrm{t}=$ sub-terminal, $\mathrm{t}=$ telson, $\mathrm{tr}=$ terminal.

\begin{tabular}{|c|c|c|c|c|c|c|c|c|}
\hline & \multicolumn{3}{|c|}{ last unit } & \multicolumn{4}{|c|}{ anus location } & \multirow[t]{2}{*}{ c.r. } \\
\hline & pt & $\mathbf{t}$ & as & b & m-v & s-t & tr & \\
\hline \multicolumn{9}{|l|}{ Pancarida } \\
\hline Thermosbaena & $x$ & & & & & & $\mathrm{X}$ & \\
\hline Tethysbaena & & $\mathrm{x}$ & & & & $\mathrm{x}$ & & \\
\hline Halosbaena & & $\mathrm{x}$ & & & $\mathrm{x}$ & & & \\
\hline Mysida & & $\mathrm{x}$ & & $\mathrm{X}$ & & & & \\
\hline Lophogastrida & & $\mathrm{x}$ & & $\mathrm{x}$ & & & & \\
\hline Pygocephalomorpha & & $\mathrm{x}$ & & $\mathrm{x}$ & & & & $\mathrm{X}$ \\
\hline \multicolumn{9}{|l|}{ Mictacea } \\
\hline Mictocaris & & $\mathrm{X}$ & & $\mathrm{X}$ & & & & \\
\hline Hirsutia & & $\mathrm{x}$ & & & & & $\mathrm{x}$ & \\
\hline \multicolumn{9}{|l|}{ Spelaeogriphacea } \\
\hline Spelaeogriphus & & $x$ & & & & (x) & $\mathrm{x}$ & \\
\hline Potiicoara & & $\mathrm{x}$ & & & & & $\mathrm{x}$ & \\
\hline Mangkurtu & & $\mathrm{x}$ & $\mathrm{x}$ & & & & $\mathrm{x}$ & \\
\hline \multicolumn{9}{|l|}{ Cumacea } \\
\hline Diastylis & & $\mathrm{x}$ & & $\mathrm{x}$ & & & & \\
\hline Pseudocuma & & $\mathrm{x}$ & & $\mathrm{x}$ & & & & \\
\hline Lamprops & & $\mathrm{x}$ & & & $\mathrm{x}$ & & & \\
\hline Allodiastylis & & $\mathrm{x}$ & & & & & $\mathrm{x}$ & \\
\hline Campylaspis & & & $\mathrm{x}$ & & & & $\mathrm{x}$ & \\
\hline Iphinoe & & & $?$ & & & & $\mathrm{x}$ & \\
\hline Nannastacus & & & ? & & & & $\mathrm{x}$ & \\
\hline Leucon & $\mathrm{x}$ & & & & $\mathrm{x}$ & & & \\
\hline \multicolumn{9}{|l|}{ Tanaidacea } \\
\hline Apseudes & ? & & ? & & & & $\mathrm{x}$ & \\
\hline fossil tanaidaceans & & $\mathrm{x}$ & & $?$ & & & $\mathrm{x}$ & \\
\hline Isopoda (except microcerberids) & $\mathrm{x}$ & & & $\mathrm{x}$ & & & $\mathrm{x}$ & \\
\hline Amphipoda -- traditional view & & $\mathrm{x}$ & & & & & $\mathrm{x}$ & \\
\hline Amphipoda -- alternative view & & & $\mathrm{X}$ & & & & $\mathrm{x}$ & $\mathrm{X}$ \\
\hline
\end{tabular}

the last body joint - not differing much from the preceding three, and 3) the anus lying between the uropods. In addition, any posterior extension that protrudes beyond the points of attachment of the uropods is missing in microcerberids. Altogether, these lead us to conclude that at least in Microcerberidae there is no telson (and therefore no pleotelson).

Similar to Microcerberidae, Phreatoicidea are adapted to a distinctive set of habitats. They occur in freshwater (springs, small streams, ground water) on southern hemisphere continents, excepting South America (Wilson and Keable, 2002). The anus effectively opens terminally. The posterior margin of the last body joint is truncate and no protruding extension beyond the anus is found. These features might appear to point to a missing telson. On the other hand, two characters suggest the opposite possibility of a pleotelson. First, the uropods do not occur on the body terminus. Second, a suture poste- rior to the uropods is obvious on the last body joint (see Fig. 7.8). Hence, the existence of a pleotelson in phreatoicids seems probable (Erhard, 1998).

Amphipoda remain distinctive. It appears that the amphipod 'telson' is attached to the last segment of the pleon, separate from and dorsal to the anus, i.e., the anus is located on the posterior aspect of pleomere six and not on the ventral side of the telson. Furthermore, consideration of the ontogeny of this region suggests an alternative hypothesis to the traditional view as to how this character may have developed. First, there is clear indication that in the ontogeny of the amphipod pleon, eight 'units' appear. There could be alternative ways to interpret these units: seven 'somites' + a presumptive telson; or eight 'somites'. It is clear that the structures that form what is called the telson in the adult amphipod arise as separate, paired out-growths from that eighth unit, and the proctodeal invagination occurs in between these out- 

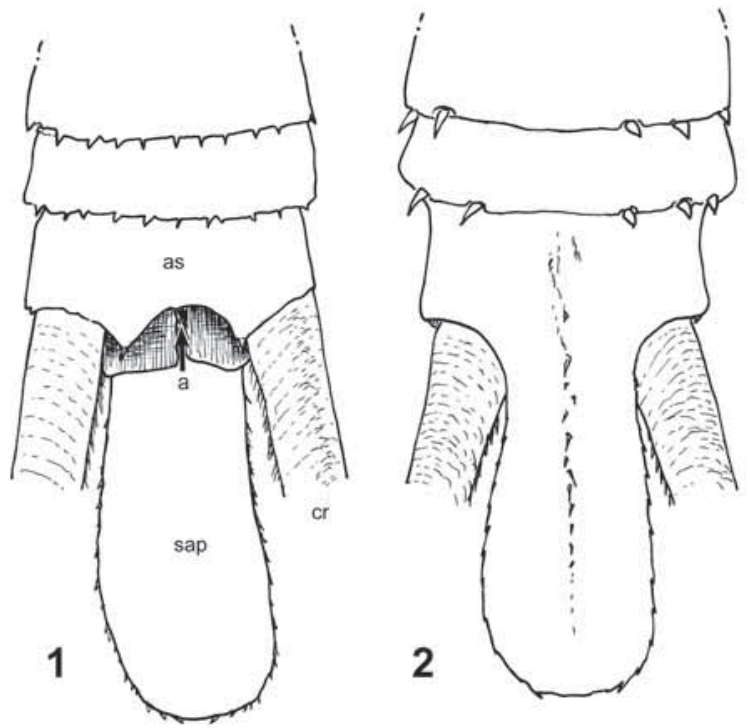

Fig. 10. Notostraca (Branchiopoda), Lepidurus apus. (1) Ventral view of caudal region. (2) Dorsal view of caudal region. a = anus, as = anal somite, $\mathrm{cr}=$ cerci, sap = supra-anal plate.

growths. One could interpret these paired elements as the Anlagen of caudal rami, i.e., not a homolog of the telson at all.

However, the fate of the eighth unit remains ambiguous. As the embryo grows, the sixth pleomere with its attendant uropods, the paired outgrowths, and the anus enlarge at the expense of the tissues associated with the seventh and eighth units.

The result of these ontogenetic events is obvious: the adult amphipod has a sixth pleomere bearing a terminal anus, and an articulated (sometimes cleft or paired) structure dorsal to that anus. Two interpretations could be advanced. One is that the embryologic eighth unit is the actual telson, which survives into the adult stage only as the paired outgrowths that come to lie dorsally. Another is that the embryologic eighth unit is an anal somite in the sense of Bowman and that the paired out-growths are the caudal rami associated with that anal somite. It would help to know what happens inside the embryo as these external structures develop. For instance, how many ganglia Anlagen arise, and where are these in relation to the ectodermal units? What is the fate of these Anlagen? What is the engrailed striping pattern in this area? Such information would help determine both the identity as well as the fate of the seventh and eighth embryonic units vis-a-vis somites in the adult amphipod.

Until these questions can be answered, it appears that the Amphipoda exhibit a distinct body plan in which the presumptive telson quite possibly disappears. The adult amphipod urosome then comes to be characterized by three sets of uropods, three segments (one of which is a terminal anal somite), and a set of caudal rami (which sometimes can fuse to form a caudal plate). A point of advantage of such an interpretation of the amphipod urosome is that it in principle accords with the development in the decapod Cherax. There, as has been pointed out, a seventh and eighth (and possibly even a ninth) engrailed stripe (Scholtz, 1995) and associated seventh and eighth ganglia Anlagen fuse with the Anlage of the sixth. This, in turn, accords with the conclusions of Sharov (1966) and Bowman (1971) that phyllocarids have eight somites in their pleon. We might then conclude that the basic number of pleon somites in the ground pattern of malacostracans would be eight, rather than seven. Of course, these hypotheses need to be corroborated, but they suggest a profitable line of research regarding malacostracan ontogeny. For example, patterns of expression of developmental genes could be used to explore alternative hypotheses regarding the homology of structures in the amphipod urosome.

\section{Conclusions}

We have investigated the pan- and peracarid eumalacostracans with regard to the nature of their urosomes. This region of the body was said to consist of a separate telson, a pleotelson, or simply the terminal anal somite. The pleon in pera- and pancarid eumalacostracans in fact exhibits for the urosome some of the most variable of morphologies of any group of crustaceans. The pleon in many of these animals exhibits six segments plus a telson. However, this telson can be either free, or fused to the last (or to several) pleomere(s) to form a pleotelson. Bowman's definition of what constitutes an anal somite, and what is a true telson, while controversial, is not without merit, but it has turned out not to be fully correct in its original form. Examination of several taxa has revealed a great degree of morpho- 
logic variability of the urosome. The position of the anus differs from being basal, through intermediate, to terminal in location - even when the anus is on a separate, true telson.

Our study illustrates yet again the need for careful and close examination of anatomy, consideration of conditions found in fossil forms, and the efficacy of studies of comparative embryology. Defining a telson, pleotelson, or last pleonal (anal) somite is difficult in fact for many peracarid groups, and we believe it is hindered by an automatic invocation of traditional definitions without concern for what is actually present. Indeed, the existence of a telson (or pleotelson) in some of the species we have investigated remains ambiguous.

For future research, investigation of other groups is critical. The careful study of syncarid eumalacostracans, especially bathynellaceans, will be central to any understanding of the eumalacostracan urosome. Consideration of notostracans and the 'conchostracans', amongst the branchiopods, will also prove instructive.

We feel confident, nevertheless, that the recognition of the body terminus as a special region, the urosome, worthy of study in its own right will lead to more effective insights to crustacean body plans, and these will find direct application in analyses of phylogeny and recognition of higher taxa. It is not important if something is true or false. What is important is to document what variation exists in the urosomal region of the pan-peracarid clade as a means of establishing a basis for further discussions of the structural variation, functional morphology, and possible phylogenetic significance of this region. We believe, along with Makarov, that it is more important to analyze real anatomical pattern, rather than relying on theory, as a step towards organizing the information available concerning variation in animal body plans.

\section{Acknowledgements}

We want to extend special thanks to Prof. dr Gerhard Scholtz for his encouragement in this work and his making possible the exchange visits of FK to the University of Amsterdam, and FRS and SK to Humboldt University. Additional thanks should go to Sven Lange and two anonymous reviewers for im- proving the manuscript, and Jan van Arkel for help with the figures. Dirk Platvoet assisted with Scanning Electron Microscopy, and Xu Sen took some additional SEMs of spelaeogriphaceans and amphipods. Special thanks go to Dr Mark Grygier, Lake Biwa Museum, Japan, for translating the article by Rodion Makarov from the original Russian. The project was supported by the European Union, SOCRATES Exchange Program, to the Humboldt University, Berlin and the University of Amsterdam.

\section{References}

Anderson DT. 1973. Embryology and phylogeny in annelids and arthropods. Pergamon Press, Sydney.

Bishop JDD. 1980. Notes on the genus Ceratocuma Calman (Crustacea, Cumacea), with a description of C. cyrtum sp. nov. J. Nat. Hist. 14: 373-388.

Bowman TE. 1971. The case of the nonubiquitous telson and the fraudulent furca. Crustaceana 21: 165-175.

Bowman TE, Iliffe TM. 1985. Mictocaris halope, a new unusual peracaridan crustacean from marine caves on Bermuda. J. Crust. Biol. 5: 58-73.

Brusca RC, Wilson GDF. 1991. A phylogenetic analysis of the Isopoda with some classificatory recommendations. Mem. Queensl. Mus. 31: 143-204.

Bückle-Ramirez, LF. 1965. Untersuchungen über die Biologie von Heterotanais oerstedi. Z. Morph. Okol. Tiere. 55: 57-78.

Calman WT. 1909. Crustacea. In: Lankester ER, ed. A Treatise on Zoology 7. Adam and Charles Black, London, 29-55.

Carlton CE, Schmitz E. 1989. Anatomy of the extrinsic gut musculature of Gammarus minus (Crustacea: Amphipoda). J. Morphol. 200: 87-92.

Dohrn A. 1870. Untersuchungen über Bau und Entwicklung der Arthropoden. Jena Z. Naturw. 1870: 54-81.

Erhard F. 1998. Morphological and philogenetical studies in the Isopoda (rustacea). Part I: The pleon trunk in the Phreatoicidea Stuttgarter Beitr. Naturk. 581: 1-42.

Gerken S. 2001. The Gynodiastylidae (Crustacea: Cumacea). Mem. Mus. Victoria 59: 1-247.

Gilbert SF. 1997. Arthropods: the crustaceans, spiders, and myriapods. In: Gilbert SF, Raunio AM, eds. Embryology: Constructing the Organism. Sinauer, Sunderland: 237-257.

Gordon I. 1957. On Spelaeogriphus, a new cavernicolous crustacean from South Africa. Bull. Brit. Mus. (Nat. Hist.), (Zool.) 5: 31-47.

Gutu M. 2001. Emendations on the description of Thetispelecaris remex Gutu and Iliffe, 1998 and the diagnosis of the order Bochusacea (Crustacea: Peracarida). Trav. Mus. Hist. Nat. 'Grigore Antipa'. 43: 47-57.

Gutu M, Iliffe TM. 1998. Description of a new hirsutiid (n.g., n. sp.) and reassignment of this family from order Mictacea to the new order, Bochusacea (Crustacea, Peracarida). Trav. Mus. Hist. Nat. 'Grigoire Antipa' 40: 93-120. 
Gutu M, Sieg J. 1999. Ordre des tanaïdacés (Tanaidacea Hansen, 1895). In: Forest J, ed. Traité de Zoologie. Anatomie, Systématique, Biologie. Tome 7, Crustacés, Fascicule 3A, Péracarides. Mém. Inst. Océanogr. Monaco 19: 353-389.

Grüner H-E. 1993. Überordnungen Pancarida und Peracarida. In Kaestner A, Lehrbuch der Speziellen Zoologie, Band I: Wirbellose Tiere, 4. Teil: Arthropoda (ohne Insecta). Grüner H-E, ed: 448-1009. Gustav Fischer Verlag, Jena Stuttgart New York.

Haye PA, Kornfield I, Watling L. 2004. Molecular insights in cumacean family relationships (Crustacea: Cumacea). Mol. Phyl. Evol. 30: 798-809.

Hennig W. 1986. Articulata, Gliedertiere. In: Wirbellose II. Gustav Fischer Verlag Jena, 11.

Just J, Poore GCB. 1988. Second record of Hirsutiidae (Peracarida: Mictacea): Hirsutia sandersetalia, new species, from southeastern Australia. J. Crust. Biol. 8: 483-488.

Johnson, SB. 1982. Functional models, life history, and evolution of tube-dwelling Tanaidacea. Doctoral dissertation, University of Lund.

Makarov RR. 1978. The caudal tagma of higher crustaceans: its biological specificity and origin. J. Gen. Biol. 39: 927-939. (in Russian)

Manton SM. 1928. On the embryology of a mysid crustacean, Hemimysis lamornae. Phil. Trans. R. Soc. (B) 216: 363-463.

McMurrich JP. 1895. Embryology of the isopod Crustacea. J. Morphol. 11: 63-154.

Monod J, Cals P. 1999. Ordre des Thermosbaenacés. Mem. Inst. Oceanogr., Monaco 19: 11-34.

Nair KB. 1939. The reproduction, oögenesis and development of Mesopodopsis orientalis TATT. Proc. Indian Acad. Sci. 9: 175-223.

Nair SG. 1956. On the embryology of the isopod Irona. J. Embryol. Exp. Morph. 4: 1-33.

Ohtsuka S, Hanamura Y, Kase T. 2002. A new species of Thetispelecaris (Crustacea: Peracarida) from submarine cave on Grand Cayman Island. Zool. Sci. 19: 611-624.

Patel NH. 1994. The evolution of arthropod segmentation: insights from comparison of gene expression patterns. Development Supplement: 201-207.

Petrescu I. 1994. Contributions to the knowledge of Leucon genus (Crustacea: Cumacea) from the waters of South America. Trav. Mus. Hist. Nat. 'Grigore Antipa' 34: 325-345.

Richter S, Scholtz G. 2001. Phylogenetic analysis of the Malacostraca (Crustacea). J. Zool. Syst. Evol. Res. 39: 113-136.

Roman M-L, Dalens H. 1999. Ordre des Isopodes (Épicarides exclus) (Isopoda Latreille, 1817). In: Forest J, ed. Traité de Zoologie. Anatomie, Systématique, Biologie. Tome 7, Crustacés, Fascicule 3A, Péracarides. Mém. Inst. Océanogr. Monaco 19: 177-278.

Sanders HL, Hessler RR, Garner SP. 1985. Hirsutia bathyalis, a new unusual deep-sea benthic peracaridan crustacean from the tropical Atlantic. J. Crust. Biol. 5: 30-57.

Schminke HK. 1976. The ubiquitous telson and the deceptive furca. Crustaceana 30: 292-300.

Scholl G. 1963. Embryologische Untersuchungen an Tanaidaceen (Heterotanais oerstedi Kröyer). Zool. Jb. Anat. 80: 500554.
Scholtz G. 1990. The formation, differentiation and segmentation of the post-naupliar germ band of the amphipod Gammarus pulex L. (Crustacea, Malacostraca, Peracarida). Proc. R. Soc. Lond. (B) 239: 163-211.

Scholtz G. 1992. Cell lineage studies in the crayfish Cherax destructor: germ band formation, segmentation, and early neurogenesis. Roux's Arch. Dev. Biol. 202: 36-48.

Scholtz G. 1993. Teloblasts in decapod embryos: an embryonic character reveals the monophyletic origin of freshwater crayfishes. Zool. Anz. 230: 45-54.

Scholtz G. 1995. Expression of the engrailed gene reveals nine putative segment-Anlagen in the embryonic pleon of the freshwater crayfish Cherax destructor (Crustacea, Malacostraca, Decapoda). Biol. Bull. 188: 157-165.

Scholtz G. 2000. Evolution of the nauplius stage in malacostracan crustaceans. J. Zool. Syst. Evol. Research 38: 175-187.

Scholtz G, Dohle W. 1996. Cell lineage and cell fate in crustacean embryos - a comparative approach. Int. J. Dev. Biol. 40: 211-220.

Schram FR. 1986. Crustacea. Oxford University Press.

Schram FR, Sieg J, Malzahn E. 1986. Fossil Tanaidacea. Trans. S. Diego Soc. Nat. Hist. 21: 127-144.

Schram FR, Hof CHJ. 1998. Fossils and the interrelationships of major crustacean groups. In: Edgecombe GD, ed. Arthropod Fossils and Phylogeny. Columbia University Press, New York, 233-302.

Serban E. 1972. Bathynella (Podophallocarida: Bathynellacea). Trav. Inst. Speol. 'Emile Racovitza' 11: 11-224.

Sharov AG. 1966. Basic Arthropodan Stock, with Special Reference to Insects. Pergamon Press, Oxford.

Siewing R. 1963. Zur Morphologie der aberranten Amphipodengruppe Ingolfiellidae und zur Bedeutung extremer Kleinformen für die Phylogenie. Zool. Anz. 171: 76-91.

Strömberg J-O. 1965. On the embryology of the isopod Idotea. Ark. Zool. 17: 421-473.

Strömberg J-O. 1972. Cyathura polita (Crustacea, Isopoda), some embryological notes. Bull. Mar. Sci. 22: 463-482.

Ungerer P, Wolff C. 2005. External morphology of limb development in the amphipod Orchestia cavimana (Crustacea, Malacostraca, Peracarida). Zoomorphology 124: 8999.

Wägele JW. 1989. Evolution und phylogenetisches System der Isopoda. Stand der Forschung und neue Erkenntnisse. Zoologica 140: 1-262.

Wagner HP. 1994. A monographic review of the Thermosbaenacea (Crustacea: Peracarida) - a study on their morphology, taxonomy and biogeography. Zool. Verh. 291: 1-338.

Watling L. 1999. Towards understanding the relationships of the peracaridan orders: the necessity of determining exact homologies. In: Crustaceans and the Biodiversity Crisis. Proc. Fourth Int. Crustacean Congress, Amsterdam: The Netherlands, July 20-24, 1998, Schram FR; von Vaupel Klein J.C., eds: 73-89. Brill Publ., Leiden.

Westheide W, Rieger R. 1996. Spezielle Zoologie. Teil 1: Einzeller und wirbellose Tiere. Gustav Fischer Verlag, Jena, Stuttgart, New York 1996.

Weygoldt P. 1958. Die Embryonalentwicklung des Amphipoden Gammarus pulex pulex (L). Zool. Jb. Anat. 77: 51-110. 
Wilson GDF, Keable SJ. 2002. New Phreatoicidea (Crustacea: Isopoda) from Grampians National Park, with revisions of Synamphisopus and Phreatoicopsis. Mem. Mus. Victoria 59: 457-529.

Wolff G, Scholtz G. 2002. Cell lineage, axis formation, and the origin of germ layers in the amphipod crustacean Orchestia cavimana. Developmental Biol. 250: 44-58.

Zilch R. 1974. Die Embryonalentwicklung von Thermosbaena mirabilis Monod (Crustacea, Malacostraca, Pancarida). Zool. Jb. Anat. 93: 462-576.
Zilch R. 1975. Etappen der Frühontogenese von Thermosbaena mirabilis Monod (Crustacea, Malacostraca, Pancarida). Verh. Dtsch. Zool. Ges. 67: 121-126.

Zimmer C. 1980. Cumaceans of the American Atlantic boreal coast region (Crustacea: Peracarida). Smithson. Contrib. Zool. 302: 1-29.

Received: 21 March 2006

Accepted: 6 April 2006 
